Conclusion: Our results add evidence for the presence of polyautoimmnunity and major organ involvement in SjS. We found a slightly lower prevalence of polyautoimmunity and major organ involvement compared to recently reported data (2). Nonetheless, extra-glandular organ involvement should be assessed in order to elucidate cumulative damage and how it might impact outcome, prognosis and therapeutic approaches in SjS.

\section{REFERENCES}

[1] Shiboski SC, et al. American College of Rheumatology classification criteria for Sjögren's syndrome: a data-driven, expert consensus approach in the Sjögren's International Collaborative Clinical Alliance cohort. Arthritis Care Res (Hoboken) 2012;64(4):475-87.

[2] Both T, et al. Reviewing primary Sjögren's syndrome: beyond the dryness - From pathophysiology to diagnosis and treatment. Int J Med Sci. (2017) 23;14(3):191-200.

Disclosure of Interests: Larissa Valor: None declared, Hannah Schenker : None declared, Melanie Hagen: None declared, Johannes Knitza: None declared, Jürgen Rech Grant/research support from: Bristol-Myers Squibb and Celgene (greater than $\$ 10,000$ ), Consultant for: Bristol-Myers Squibb, Celgene, Chugai, GlaxoSmithKline, Janssen, Eli Lilly, Novartis, Roche, Sanofi Aventis, and UCB (in total more than $\$ 10,000$ ), Speakers bureau: Bristol-Myers Squibb, Celgene, Chugai, GlaxoSmithKline, Janssen, Eli Lilly, Novartis, Roche, Sanofi Aventis, and UCB (in total more than $\$ 10,000$ ), Georg Schett: None declared

DOI: 10.1136/annrheumdis-2019-eular.3664

\section{AB0567 DISEASE PATTERN IN EARLY AND NON-EARLY SYSTEMIC LUPUS ERYTHEMATOSUS}

Sadovici-Bobeica Victoria ${ }^{1}$, Maria Garabajilu ${ }^{2}$, Lucia Mazur-Nicorici ${ }^{2}$, Mariana Cebanu', Virginia Salaru', Minodora Mazur'. 'State University of Medicine and Pharmacy "Nicolae Testemitanu", Rheumatology, Chișinău, Moldova, Republic of, ${ }^{2}$ State University of Medicine and Pharmacy "Nicolae Testemitanu", Chișinău, Moldova, Republic of

Background: Systemic lupus erythematosus (SLE) is an autoimmune disease with a high degree of variability at onset, creating challenges in the accurate estimation of it's pattern in early stages ${ }^{1}$.

Objectives: To evaluate the pattern of the disease in patients with early and non-early systemic lupus erythematosus from physician's perspective. Methods: Performed case-control study included SLE patients that fulfilled SLICC classification criteria, 2012. The research included two groups: patients with early SLE $-1^{\text {st }}$ group (disease duration $\leq 24$ months) and non-early SLE $-2^{\text {nd }}$ group (disease duration 24 months). The pattern of the disease activity was assessed by SLEDAI-2K, SLAM, PGA and PhGA for SLE activity, SLICC/ACR DI for disease irreversible changes and SF-8 for the quality of life (QoL). We correlated disease activity scores within groups and activity indices with the QoL using intra- and inter-class correlation coefficients

Results: A total of $101 \mathrm{SLE}$ patients was analyzed. First group (early SLE) included 34 patients while the second group (non-early SLE) included 67 patients. The disease duration \pm SD (range) was 12,42 $+8,70$ (0.1-24) and 146,41 $\pm 81,64$ (31-432) months, respectively. The disease activity was high in both groups. The QoL was appreciated as low, compared to general population, by both components, in 2 groups. The damage index was higher in the 2nd group, which can be explained by longer disease duration and development of irreversible changes during the course of lupus.

The PhGA showed stronger and higher correlation with disease activity and QoL in patients with longer disease duration. These can be explained by the more accurate assessment of patients that have longer disease duration, while the unpredictable evolution and the assessment of early SLE is being challenging for the physician. Also, physician's judgment was influenced by the presence of irreversible organ damage in patient with longer disease, while in early disease course they where concerned mostly about disease activity.

Conclusion: The clinical picture of SLE was characterized by high disease activity and low QoL in both, early and non-early lupus, while occurrence of irreversible organ changes was more characteristic for the longer disease. The disease parameters (activity, damage and QoL) correlated with PhGA mostly in patients with non-early SLE, the appreciation of the disease pattern being challenging in the early disease course.

\section{REFERENCES}

[1] Cervera R. et al. Lessons from the "Euro-Lupus Cohort". Ann Med Interne, 2012 Dec;153(8):530-6

Table 1. General characteristic of the study group

\begin{tabular}{lccc}
\hline Parameters of the disease & Gr I, Nr 34 & Gr II, Nr 67 & p \\
\hline SLAM \pm SD (range), points & $7,47 \pm 4,40(0-24)$ & $7,31 \pm 4,10(1-19)$ & $>0,05$ \\
SLEDAI \pm SD (range), points & $7,02 \pm 4,16(0-17)$ & $6,26 \pm 4,43(0-18)$ & $>0,05$ \\
PhGA \pm SD (range), points & $45,61 \pm 19,45(10-82)$ & $48,35 \pm 19,50(5-$ & $>0,05$ \\
& & $82)$ & \\
PGA \pm SD (range), points & $46,97 \pm 19,39(10-93)$ & $47,98 \pm 22,41(5-$ & $>0,05$ \\
& & $90)$ & \\
SLICC/ACR DI & $0,23 \pm 0,43(0-1)$ & $1,07 \pm 1,29(0-5)$ & $<0,001$ \\
SF-8 \pm SD, points & $38,79 \pm 10,6041,80$ & $36,76 \pm 10,33$ & $>0,05$ \\
PCS (physical component & $\pm 10,83$ & $41,97 \pm 10,47$ & $>0,05$ \\
status) & & & \\
MCS (mental component status) & & &
\end{tabular}

Table 2. Correlation of PhGA with other SLE parameters

\begin{tabular}{lcc}
\hline & $\begin{array}{c}\text { Early SLE group PhGA } \\
\text { (correlation coefficient } r \text { ) }\end{array}$ & $\begin{array}{c}\text { Non-early SLE group PhGA } \\
\text { (correlation coefficient } r \text { ) }\end{array}$ \\
\hline PGA & $0,86^{*}$ & $0,81^{*}$ \\
SLAM & $0,48^{* * *}$ & $0,60^{*}$ \\
SLEDAI & 0,20 & $0,50^{*}$ \\
SF-8 PCS & $0,56^{*}$ & $0,54^{*}$ \\
SF-8 MCS & $0,41^{* *}$ & $0,50^{*}$ \\
SLICC/ACR DI & 0,12 & $0,37^{* *}$ \\
${ }^{*}<0,001^{* *}<0,01^{* * *}<0,05$ & &
\end{tabular}

Disclosure of Interests: None declared

DOI: 10.1136/annrheumdis-2019-eular.4677

\title{
AB0568 THE EFFECT OF DEPRESSIVE AND ANXIETY ON QUALITY OF LIFE IN PATIENT WITH SYSTEMIC LUPUS ERYTHEMATOSUSIN RENAISSANCE COHORT
}

Lyubov Vorobyova, Elena Aseeva, Sergey Solovyev. V.A.Nasonova Research Institute of Rheumatology, Intensive care department, Moscow, Russian Federation

Background: Systemic lupus erythematosus (SLE) patients are at high risk of depression and anxiety. These two states cause severe loss of health related quality of life (HRQoL) for patient with SLE.

Objectives: The aim of the current study was to assess the effect of depressive and anxiety on HRQoL in a cohort of patients with systemic lupus erythematosus in Russian Federation (RENAISSANCE).

Methods: Consecutive patients who fulfilled SLICC 2012 criteria for SLE were recruited. Depressive and anxiety symptoms were assessed by the Hospital Anxiety and Depression (HAD) scale (0-21 points). Health-related quality of life (HRQoL) was assessed by the validated specific questionnaires LupusQoL-Russian. Disease activity was evaluated by the SLEDAI$2 \mathrm{~K}$, and chronic damage by the Systemic Lupus International Collaborating Clinics Damage Index score (SDI).

Results: 328 Russian SLE patients were enrolled in the study (M/F 30/ 298, mean age $34.4 \pm 11.5$ years, mean disease duration $106.3 \pm 97.9$ months; mean SLEDAI $2 \mathrm{~K}$ 9.6 \pm 8.0 ; mean SDI $0.2 \pm 0.6$. $34(10,3 \%)$ patients had HADS-depression score of $\geq 10$ and $76(23,1 \%)$ of patients had HADS-anxiety score of $\geq 10$. Patients with depressive score of $\geq 10$ had significantly lower the scales "Planning", "Emotion health" and "Fatigue" $(p<0,0001)$ of the LupusQoL than those with score $<10$. Similarly, significant lower "Emotion health" and "Fatigue" $(p<0,0001)$ were noted in those patients with HAD-anxiety score $\geq 10$ compared to those $<10$ and they also had low score of "Burden to others" unlike those who are not anxiety. (Table 1).

Conclusion: Depressive and anxiety symptoms in SLE patients and were associated with significantly poorer HRQoL.

Table 1. Effect of anxiety and depressive on HRQoL in SLE patient

\begin{tabular}{|c|c|c|c|c|c|c|}
\hline $\begin{array}{l}\text { LupusQol } \\
\text { domains }\end{array}$ & $\begin{array}{c}\text { HADS- } \\
\text { anxiety<10 }\end{array}$ & $\begin{array}{l}\text { HADS- } \\
\text { anxiety } \\
\geq 10\end{array}$ & $p$ & $\begin{array}{c}\text { HADS - } \\
\text { depressive }<10\end{array}$ & $\begin{array}{c}\text { HADS- } \\
\text { depressive } \\
\geq 10\end{array}$ & $p$ \\
\hline $\begin{array}{l}\text { Physical } \\
\text { health }\end{array}$ & $70,3 \pm 22,2$ & $\begin{array}{r}50,2 \\
\pm 21,2\end{array}$ & $<0,0001$ & $67,9 \pm 23,1$ & $48,2 \pm 18,7$ & $<0,0001$ \\
\hline Pain & $73,8 \pm 23,3$ & $52 \pm 22,3$ & $<0,0001$ & $71,2 \pm 23,8$ & $50,7 \pm 26,9$ & $<0,0001$ \\
\hline Planning & $68,4 \pm 26,8$ & $\begin{array}{c}42,8 \\
\pm 26,3\end{array}$ & $<0,0001$ & $65,8 \pm 21,2$ & $35,3 \pm 21,2$ & $<0,0001$ \\
\hline $\begin{array}{l}\text { Intimate } \\
\text { relationship }\end{array}$ & $75,9 \pm 30,6$ & $\begin{array}{c}56,7 \\
\pm 29,8\end{array}$ & $<0,0001$ & $73,2 \pm 31,1$ & $58,3 \pm 33,6$ & 0,05 \\
\hline
\end{tabular}




\begin{tabular}{|c|c|c|c|c|c|c|}
\hline $\begin{array}{l}\text { Burden to } \\
\text { others }\end{array}$ & $60,4 \pm 27,2$ & $\begin{array}{r}39,5 \\
\pm 23,1\end{array}$ & $<0,0001$ & $57,7 \pm 27,3$ & $42 \pm 29,9$ & 0,001 \\
\hline $\begin{array}{l}\text { Emotion } \\
\text { health }\end{array}$ & $70,8 \pm 21,2$ & $37,9 \pm 22$ & $<0,0001$ & $66,6 \pm 24,2$ & $40,1 \pm 20,3$ & $<0,0001$ \\
\hline Body image & $69,8 \pm 25,7$ & $48 \pm 27,6$ & $<0,0001$ & $67 \pm 26,8$ & $45,7 \pm 28,6$ & 0,001 \\
\hline Fatique & $67,9 \pm 22,4$ & $40 \pm 22,4$ & $<0,0001$ & $64,4 \pm 24,3$ & $41 \pm 21,7$ & $<0,0001$ \\
\hline
\end{tabular}

Disclosure of Interests: None declared

DOI: 10.1136/annrheumdis-2019-eular.4523

\section{AB0569 THE EFFECT OF CUTANEOUS AND MUSCULOSKELETAL SYMPTOMS ON QUALITY OF LIFE IN PATIENT WITH SYSTEMIC LUPUS ERYTHEMATOSUS IN RENAISSANCE COHORT}

Lyubov Vorobyova, Elena Aseeva, Sergey Solovyev. V.A.Nasonova Research Institute of Rheumatology, Intensive care department, Moscow, Russian Federation

Background: Cutaneous and musculoskeletal symptoms is one of the most frequent clinical complaints of patients with systemic lupus erythematosus(SLE) and has been found to occur in up to $70 \%-95 \%$ of patients during the course of the disease. For these reasons, SLE can affect different aspects of the patient's life, leading to an impairment of HRQOL.

Objectives: The aim of the current study was to assess the effect of cutaneous and musculoskeletal symptoms on HRQoL in a cohort of patients with systemic lupus erythematosus in Russian Federation (RENAISSANCE).

Methods: Consecutive patients who fulfilled SLICC 2012 criteria for SLE were recruited. Health-related quality of life (HRQoL) was assessed by the validated specific questionnaires LupusQoL-Russian. Disease activity was evaluated by the SLEDAI-2K, and chronic damage by the Systemic Lupus International Collaborating Clinics Damage Index score (SDI).

Results: 328 Russian SLE patients were enrolled in the study (M/F 30/ 298, mean age $34.4 \pm 11.5$ years, mean disease duration $106.3 \pm 97.9$ months; mean SLEDAI $2 \mathrm{~K}$ 9.6 \pm 8.0 ; mean SDI $0.2 \pm 0.6$. Musculoskeletal symptoms were observed in 142 patients, cutaneous and mucosal lesion symptoms -147 patients, respectively. When comparing HRQOL in patients with lesions skin and mucousal revealed (Table 1) significant decline HRQoL on the scales "Planning" (58.5 \pm 28.9), "Intimate Relationships" (65.9 \pm 32.1), "Burden to other" (52.9 \pm 26$)$ and "Body Image" (57.4 \pm 29.1) of the LupusQol questionnaire compared with the patients without skin and mucosal lesions $(p \leq 0.002 ; p \leq 0.001 ; p \leq 0.03 ; p \leq 0,0001$ respectively). When evaluating HRQoL in patients with SLE and musculoskeletal symptoms (Table 2) reduction of almost all scales LupusQoL.

Conclusion: Cutaneous and musculoskeletal symptoms in SLE patients were associated with significantly poorer HRQoL.

Table 1. Dependence of indicators of the scales of the LupusQol on the presence of the skin and mucosal lesions $(\mathrm{p}<0.05)$.

\begin{tabular}{lccc}
\hline LupusQoL & $\begin{array}{c}\text { No involved skin and mucosal } \\
\text { lesions }(\mathbf{N}=\mathbf{1 8 1})\end{array}$ & $\begin{array}{c}\text { Involved skin and } \\
\text { mucosals lesions } \\
\mathbf{( N = 1 4 7 )}\end{array}$ & $\mathbf{P}$ \\
\hline $\begin{array}{l}\text { Physical } \\
\text { health }\end{array}$ & $68,03 \pm 23$ & $65,03 \pm 23,5$ & 0,2 \\
Pain & $66,2 \pm 26,7$ & $62,6 \pm 21,8$ & 0,2 \\
Planning & $72,19 \pm 25$ & $67,2 \pm 24$ & 0,07 \\
Intimate & $64 \pm 24,6$ & $61 \pm 24,8$ & 0,3 \\
relationship & $68,1 \pm 27,4$ & $58,5 \pm 28,9$ & 0,002 \\
$\begin{array}{l}\text { Burden to } \\
\text { others }\end{array}$ & $78,4 \pm 29$ & $65,9 \pm 32$ & 0,001 \\
$\begin{array}{l}\text { Emotion } \\
\text { health }\end{array}$ & $59,5 \pm 29$ & $52,9 \pm 26$ & 0,03 \\
Body image & $71,7 \pm 24$ & $57,4 \pm 29$ & $<0,0001$ \\
Fatigue & & & \\
\hline
\end{tabular}

Table 2. The dependence of the indicators of the questionnaire scales LupusQoL from musculoskeletal symptoms $(p<0.05)$.

\begin{tabular}{lccc}
\hline LupusQoL & $\begin{array}{c}\text { No musculoskeletal } \\
\text { symptoms (N=186) }\end{array}$ & $\begin{array}{c}\text { musculoskeletal symptoms } \\
(\mathbf{N}=\mathbf{1 4 2})\end{array}$ & $\mathbf{p}$ \\
\hline Physical health & $69,6 \pm 23$ & $62,8 \pm 22,6$ & 0,008 \\
Pain & $67,2 \pm 28$ & $62,8 \pm 22,6$ & 0,1 \\
Planning & $74,5 \pm 24$ & $64 \pm 23,7$ & 0,001 \\
Intimate & $45,9 \pm 7,6$ & $44 \pm 7,5$ & 0,04 \\
relationship & & &
\end{tabular}

\begin{tabular}{llll}
$\begin{array}{l}\text { Burden to } \\
\text { others }\end{array}$ & $68 \pm 28,4$ & $58,3 \pm 27$ & 0,02 \\
Emotion health & $77 \pm 29,9$ & $67,2 \pm 31$ & 0,01 \\
Body image & $58,6 \pm 27$ & $54 \pm 28,6$ & 0,02 \\
Fatigue & $65,2 \pm 25$ & $59,3 \pm 23$ & 0,03 \\
\hline
\end{tabular}

Disclosure of Interests: None declared

DOI: 10.1136/annrheumdis-2019-eular.4520

\section{AB0570 CLINICAL STUDY OF THE DISEASE ACTIVITY AND IMMUNE SCREENING OF PRIMARY SJOGREN'S SYNDROME}

Yin Xufang, Zhang Mingxing, Ming Yan, LI Xiao-Feng. The Second Hospital of Shanxi Medical University, Taiyuan, China Objectives: To evaluate the change features of peripheral blood lymphocyte subsets and disease activity in patients with primary Sjogren's syndrome before and after treatment.

Methods: A total of 30 patients with primary Sjogren's syndrome in the Department of Rheumatology from the Second Hospital of Shanxi Medical University from January 2016 to December 2018 were enrolled. According to the treatment time of patients, they were divided into baseline group, 0-3 months group, 3-6 months group, 6-12 months group, and the absolute counts of $\mathrm{T}, \mathrm{B}, \mathrm{NK}$, Th1, Th2, Th17 and regulatory $\mathrm{T}$ cells(Tregs) in peripheral blood of patients before and during the treatment were measured by flow cytometry. The ratio of various cells to Tregs was calculated as well.The primary Sjogren's syndrome disease activity was assessed according to the Sjögren's syndrome disease activity index (ESSDAI) score and compared with 30 healthy people.

Results: The Tregs counts in the disease group were significantly lower than those in the healthy control group $(p<0.05)$, and the ratio of proinflammatory lymphocytes to Tregs (Th17/Treg) was higher $(p<0.05)$. Tregs counts in peripheral blood of patients with primary Sjogren's syndrome has increased significantly after 3-month treatment,at the same time, the inflammatory index ESR was significantly lower $(p<0.05)$, the ESSDAI score was significantly lower $(p<0.05)$, and the high remission rate was maintained. However there was no statistically significant increase in Treg cell growth before treatment at 3-6 months and 6-12 months, $(p>0.05)$.
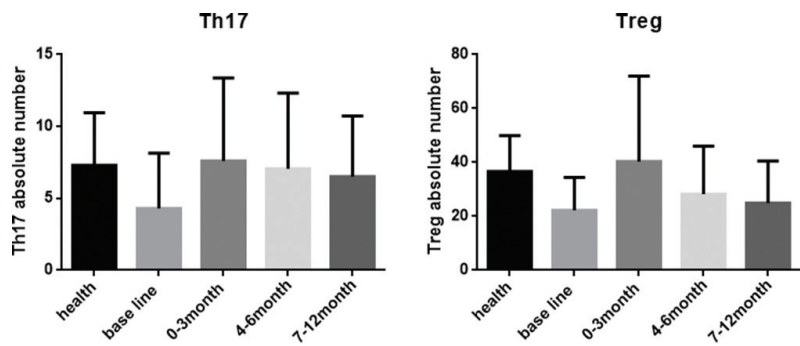

Figure 1The. Tregs counts in the disease group were significantly lower than those in the healthy control group $(p<0.05)$, and the ratio of proinflammatory lymphocytes to Tregs (Th17/Treg) was higher $(p<0.05)$.Tregs counts in peripheral blood of patients with primary Sjogren's syndrome has increased significantly after 3-month treatment.
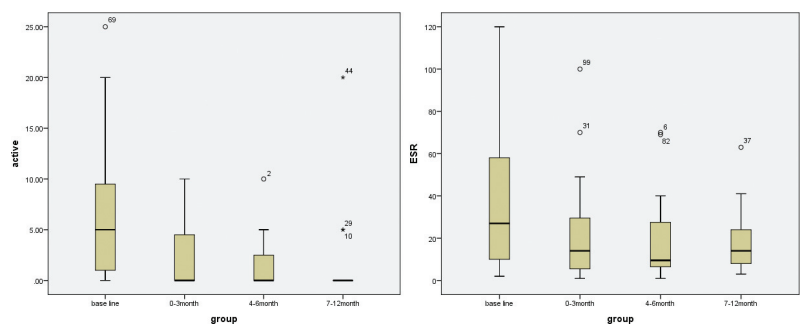

Figure 2the. inflammatory index ESR was significantly lower $(p<0.05)$, the ESSDAI score was significantly lower $(p<0.05)$, and the high remission rate was maintained.

Conclusion: The imbalance between pro-inflammatory lymphocytes and Tregs caused by the significant decrease of Tregs may be the cause of primary Sjogren's disease activity. We propose to promote the growth of Tregs and maintain the balance between pro-inflammatory lymphocytes and Tregs,which provides a new idea for disease relief of primary Sjogren's syndrome. 